\title{
Assessment of Psycho-emotional Distress Due to Age, Body Mass Index, and Marital Status in Polycystic Ovary Syndrome in North Indian Population
}

\author{
Fauzia Tabassum $^{1^{*}}{ }^{\mathbb{D}}$, Hemali Heidi Sinha ${ }^{2}$, Kavita Dhar ${ }^{1}$, Chandra Jyoti ${ }^{2}$, Md Sayeed Akhtar ${ }^{3}$, Vipender \\ Singh Chopra ${ }^{1}$
}

\begin{abstract}
Objectives: Polycystic ovary syndrome (PCOS) is a multifaceted endocrine disorder in reproductive age having a greater impact on health-related quality of life (HRQOL).

The aim of this study was to find out PCOS demographics and its related HRQOL effects for improving psychological understanding in disease management.

Materials and Methods: A prospective questionnaire-based study was conducted for a period of twelve months at All India Institute of Medical Sciences, Patna, India. The data of 100 PCOS cases were collected about socio-demographic status, clinical history, and dietary intake. Then, a validated PCOS questionnaire (PCOSQ) was used to observe the impact of PCOS symptoms on patients' HRQOL.

Results: The overall $57 \%$ and $48 \%$ of PCOS cases belonged to the age range of $20-30$ years and had a body mass index (BMI) of $>25-30$, respectively. Based on the results, a significant difference was observed in the mean score of PCOSQ vs. marital status in PCOS cases with respect to emotion $(P=0.039)$, body weight $(P=0.002)$, and infertility $(P=0.001)$. Furthermore, the result showed a significant difference in the domain of emotion $(P=0.008)$, body hair $(P=0.035)$, body weight $(P<0.001)$, and infertility $(P=0.018)$ among BMI group, and a high score was observed in the BMI group $<18$ in comparison to the other groups of BMI.

Conclusions: In general, our findings indicated that infertility, emotions, and BMI had extremely higher impacts on the HRQOL of women suffering from PCOS although their educational status failed to affect HRQOL.

Keywords: PCOS, HRQOL, Infertility, Emotion, BMI, Economic status
\end{abstract}

\section{Introduction}

According to the World Health Organization (WHO), polycystic ovary syndrome (PCOS) affected 116 million (3.4\%) women worldwide in 2012 (1) and the centre for disease control and prevention reported the most common causes of female infertility among US women at reproductive age. It comprises around 6 to 12\% (around 5 million) populations (2). In addition, PCOS has been reportedly high among Indian women similar to their Caucasian counterparts, with an estimated prevalence of around $9.13 \%-22.5 \%$ in Indian adolescents. So far, no proper published statistical data are available on the prevalence of PCOS in India $(3,4)$. Thus, PCOS is the major endocrine disorder among women in reproductive age suffering from anovulation or oligoovulation and hyperandrogenism without any other underlying condition (5). The major risk factors in PCOS women are the increased risk of psychological and reproductive problems including depression, anxiety, suicidal thoughts, infertility, endometrial cancer, and gestational problems (6-8). On the other hand, PCOS cases may cause psychological morbidity and have a significant negative impact on health-related quality of life (HRQOL) in women at reproductive age (9). PCOS cases have a greater predisposition to obesity and more adversely affect the HRQOL mainly due to infertility consequences (10). The level of hyperandrogenism and its related clinical symptoms seriously overweigh against performing daily work, as well as social activities and affecting HRQOL in young patients (11).

Currently, the due importance is given for understanding the effect of PCOS symptoms and treatment for HRQOL in PCOS cases. The variability of PCOS symptoms makes it important to understand the QOL from each patient's prospects. Furthermore, novel treatments and therapies can then be targeted toward improving psychosocial problems, which are most important for the concerned individual (12). 


\section{Key Messages}

- PCOS is a major endocrine disorder among reproductive age women, which comprises around 3.4\% population worldwide.

- Infertility, emotions and body mass index are the major observed concerns affecting the marital life and social well being.

- We recommended both therapeutic and psychological interventions to improve the compromised health related quality of life.

Psychological alterations due to infertility and cosmetic problems in PCOS cases are receiving greater attention for improving HRQOL (13-15). Moreover, compromised QOL and mood alterations including depressive symptoms, compromised sexual satisfaction, and feminine identity are among the major concerns in PCOS cases (6). Earlier, different investigators in the urban population reported various studies. However, the existence of PCOS cases and its effects on HRQOL in the young population have been least reported in diverse populations of north India. Thus, this is also of utmost importance to find out the demographics of PCOS and its related HRQOL for improving psychosocial understanding regarding disease treatment and better medical policy implementation in a particular population.

\section{Materials and Methods}

This prospective questionnaire-based HRQOL study was conducted in a tertiary care teaching hospital. Patients visiting the Department of Gynecology and Obstetrics in All India Institute of Medical Sciences, Patna, were recruited as study participants. Based on the 2003 ESHRE/ASRM (Rotterdam criteria), the set criteria for the diagnosis of PCOS was the presence of at least two out of three criteria as Oligo/anovulation, hyperandrogenism, and polycystic ovaries (8). Prior to the commencement of this study, ethical approval (Letter no.-SU/2017/126-3) was obtained from the Institutional Review Board of Santosh Medical College, Ghaziabad, India. In addition, the study site (Letter no.-176/AIIMS/Pat/IEC/2017) was approved by the Institutional Review Board of All India Institute of Medical Sciences, Patna, India.

Totally, 100 eligible PCOS patients were enrolled in this observational study. The data of participants were collected after providing all study-related written and oral information, and participants were ensured of their right to withdraw from the study at any point in time. After explaining the study, each participant was asked to sign the informed consent form and then requested to complete the questionnaires. PCOS cases were included if they were only diagnosed cases of PCOS, within the age range (from menarche to menopausal) of 10-49 years, and provided signed informed consent. Those patients who did not fulfill the above-mentioned criteria were excluded from the study. Finally, PCOS cases were excluded if they were suffering from cognitive or developmental disabilities or another major illness that had a substantial influence on the QOL of women (e.g., those with confirmed malignancy) and had deformities.

\section{Data Collection}

A face-to-face interview was conducted to fill the required questionnaires and then completed as follows:

Part A: A semi-structured, pre-validated questionnaire was used for collecting information on socio-demographic, economic, dietary habits, personal behaviours, as well as present and past medical history.

Part B: Validated PCOS Questionnaire (PCOSQ) of HRQOL, which is a specific instrument for women with PCOS, was used to outline the impact of the symptoms and sign of PCOS $(16,17)$. This questionnaire contains 26 items organised into five major domains of emotion, body hair, body weight, infertility, and menstrual problem (18). Patients were asked to choose the best-suited option for their feeling in the last 14 days. Further, the scores were in the range of 1-7 for each item and lower scores indicated a worse condition. The score of individual items comprising the domain was added and then divided by the number of questions in that domain in order to obtain the individual score. From different domains, 8 questions were related to emotion, and 5 questions belonged to body hair and body weight, and finally, 4 questions obtained data on infertility and menstrual problem. Eventually, WHO set criteria for the body mass index (BMI) cut-off, where BMI $\geq 25 \mathrm{~kg} / \mathrm{m}^{2}$ was taken into account for the Asian population.

\section{Statistical Analysis}

After editing and verification of all datasheet, data were entered into a computer using SPSS (version 22) or Excel (MS Office10) and then analyzed using statistical software-Stata, version 14.0 (Stata Corp, Texas, USA). Moreover, an appropriate statistical test was applied after checking the normality condition for continuous variables. Quantitative data were expressed as mean \pm SD and minimum and maximum. Additionally, categorical variables were presented as frequency and percentage. Similarly, Pearson chi-square and Fisher exact tests were used to check the association between qualitative and categorical variables. Likewise, independent $t$ test and one-way ANOVA were employed to compare normally distributed continuous variables between two and three categories, respectively. Finally, rank-sum/KruskalWallis test was applied to compare skewed continuous variables among categories, and a $P<0.05$ was considered statistically significant for all statistical analyses.

\section{Results}

The study group consisted of 100 women diagnosed with PCOS as per the Rotterdam criteria. Table 1 provides the number and frequency related to the demographic status 
of PCOS patients. With respect to age, the number of PCOS cases with age $\leq 19$ years was $34 \%$, whereas, that of those within the age range of 20-30 years and $>30$ was $57 \%$ and $9 \%$, respectively. Furthermore, BMI was used to measure the degree of obesity and the result showed that patients with a $\mathrm{BMI}<18$, in the range of $18-25,>25$ 30 , and $>30$ was $10 \%, 48 \%, 26 \%$, and $16 \%$, respectively. Based on the results, the maximum percentage of patients belonged to the urban area (50\%), followed by the semiurban (33\%) and rural (17\%) areas. Regarding educational status, $4 \%$ of patients were illiterate whereas $14 \%, 13 \%$, $15 \%$, and $54 \%$ of participants had literacy level of up to primary and middle sum, up to high school, intermediate and graduation and above, respectively. The results further revealed that only $5 \%$ of patients were employed or professional. Moreover, $60 \%$ and $35 \%$ of them were students and house makers, respectively. Respecting the income group, $26 \%$ and $61 \%$ of patients belonged to upper and middle classes, respectively, and only $13 \%$ of them were in the lower class category. Based on data in Table 1, the overall HRQOL score of the mean age of participants was $22.81 \pm 5.33$ and the BMI was $24.3 \pm 4.49$. Additionally, the age at marriage and menarche was $19.31 \pm 3.97$ and13.86 \pm 1.44 , respectively. Finally, the number of children and pregnancy was $1.46 \pm 0.91$ and $1.77 \pm 1.02$ in PCOS cases, respectively.

The results represented that $41 \%$ of PCOS cases were married although delayed and irregular menstrual cycles and a tendency to conceive a child were among the major concerns for seeking treatment among these cases. Based on medical history, 33\% of cases got menarche at the age of $>14$ years, and irregular and delayed menses were observed in $45 \%$ and $54 \%$ of cases, respectively. In addition, $64.3 \%$ and $2 \%$ of women had no child and were suffering from a miscarriage in their medical history, respectively. Regarding the duration of PCOS symptoms in women, $43 \%$ of them had problems during $<1$ year, $47 \%$ between 1 and 5 years, and $10 \%$ of cases had problems from even $>5$ years (Table 2 ).

Data related to the dietary habit of PCOS patients (Table 2) revealed that among 100 PCOS cases, 30\% and $70 \%$ were pure vegetarian and mixed cases (vegetarian and non-vegetarian), respectively. With respect to eating different types of junk foods, only $7 \%$ of cases were eating more than 4 types of junk foods and $90 \%$ of them were taking 2-4 types of junk foods although only $3 \%$ of cases were consuming 2 types of junk foods. As regards the eating frequency of junk foods, only $2 \%$ of cases were taking junk foods on daily basis. In terms of frequency, $32 \%$ and $33 \%$ of cases were taking 1 time or two times in a week and once in four weeks, respectively, and 33\% of them took junk foods occasionally.

Table 3 summarizes the overall mean score of PCOSQ in PCOS cases. Based on the results, the lowest score was related to infertility and emotion while the highest score belonged to body hair, body weight, and menstrual
Table 1. Number and Frequency Related to the Demographic Status of PCOS Patients

\begin{tabular}{|c|c|}
\hline Variables & PCOS \\
\hline \multicolumn{2}{|l|}{ Age (y), No. (\%) } \\
\hline$\leq 19$ & $34(34.0)$ \\
\hline $20-30$ & $57(57.0)$ \\
\hline$>30$ & $9(9.0)$ \\
\hline \multicolumn{2}{|l|}{ BMI, No. (\%) } \\
\hline$<18$ & $10(10.0)$ \\
\hline $18-25$ & $48(48.0)$ \\
\hline$>25-30$ & $26(26.0)$ \\
\hline$>30$ & $16(16.0)$ \\
\hline \multicolumn{2}{|l|}{ Area of residence, No. (\%) } \\
\hline Rural & $17(17.0)$ \\
\hline Semi-urban & $33(33.0)$ \\
\hline Urban & $50(50.0)$ \\
\hline \multicolumn{2}{|l|}{ Educational status, No. (\%) } \\
\hline Illiterate & $4(4.0)$ \\
\hline Up to primary & $7(7.0)$ \\
\hline Up to middle & $7(7.0)$ \\
\hline Up to high school & $13(13.0)$ \\
\hline Intermediate & $15(15.0)$ \\
\hline Graduation/above & $54(54.0)$ \\
\hline \multicolumn{2}{|l|}{ Occupational status, No. (\%) } \\
\hline Students & $60(60.0)$ \\
\hline House maker & $35(35.0)$ \\
\hline Employed/professionals & $5(5.0)$ \\
\hline \multicolumn{2}{|l|}{ Income groups, No. (\%) } \\
\hline Upper class & $26(26.0)$ \\
\hline Middle class & $61(61.0)$ \\
\hline Lower class & $13(13.0)$ \\
\hline Age, mean \pm SD & $22.81 \pm 5.33$ \\
\hline BMI, mean \pm SD & $24.35 \pm 5.49$ \\
\hline Age at marriage, mean $\pm S D$ & $19.31 \pm 3.97$ \\
\hline Age at menarche, mean \pm SD & $13.86 \pm 1.44$ \\
\hline Number of child, mean \pm SD & $1.46 \pm 0.91$ \\
\hline Number of times get pregnant, mean \pm SD & $1.77 \pm 1.02$ \\
\hline Variables & p50 (min-max) \\
\hline Age & $22(14-36)$ \\
\hline BMI & $24.29(11.32-38.1)$ \\
\hline Age at marriage & $20(13-30)$ \\
\hline Age at menarche & $14(11-18)$ \\
\hline No of child & $1(1-4)$ \\
\hline Number of times get pregnant & $1(1-4)$ \\
\hline
\end{tabular}

Note. PCOS: Polycystic ovary syndrome; BMI: Body mass index; SD: Standard deviation; Data are presented as frequency (percent), mean \pm SD and p50 (min-max). 
Table 2. Patient Marital Status, Medical History and Other Dietary Habits of PCOS Cases

\begin{tabular}{|c|c|}
\hline Variable & PCOS, No. (\%) \\
\hline \multicolumn{2}{|l|}{ Marital status } \\
\hline Married & $41(41.0)$ \\
\hline Unmarried & $59(59.0)$ \\
\hline \multicolumn{2}{|l|}{ Age at menarche $(\mathrm{y})$} \\
\hline$<14$ & $67(67)$ \\
\hline$>14$ & $33(33)$ \\
\hline \multicolumn{2}{|l|}{ Menstrual history } \\
\hline Regular & $1(1.0)$ \\
\hline Irregular & $45(45.0)$ \\
\hline Delayed/Late & $54(54.0)$ \\
\hline \multicolumn{2}{|l|}{ Children } \\
\hline Yes & $15(35.7)$ \\
\hline No & $27(64.3)$ \\
\hline \multicolumn{2}{|l|}{ Miscarriage/MTP } \\
\hline Yes & $12(12.0)$ \\
\hline No & $88(88.0)$ \\
\hline \multicolumn{2}{|l|}{ Duration of PCOS symptoms } \\
\hline Less than 1 year & $43(43)$ \\
\hline $1-5$ year(s) & $47(47)$ \\
\hline$>5$ years & $10(10)$ \\
\hline \multicolumn{2}{|l|}{ Dietary habits } \\
\hline Pure vegetarian & $30(30.0)$ \\
\hline Occasional non-vegetarian & $40(40.0)$ \\
\hline Non-vegetarian & $30(30.0)$ \\
\hline \multicolumn{2}{|l|}{ Eating number of junk food } \\
\hline$<2$ & $3(3.0)$ \\
\hline $2-4$ & $90(90.0)$ \\
\hline$>4$ & $7(7.0)$ \\
\hline \multicolumn{2}{|l|}{ Frequency of junk food } \\
\hline Daily & $2(2.0)$ \\
\hline 1-2 times a week & $32(32.0)$ \\
\hline Once in 4 weeks & $33(33.0)$ \\
\hline Occasionally & $33(33.0)$ \\
\hline
\end{tabular}

Note. PCOS: polycystic ovary syndrome; MTP: Medical termination of pregnancy.

problem. The mean score of these five domains of the HRQOL questionnaire was $3.58 \pm 1.66,3.73 \pm 1.06$, $4.05 \pm 0.71,4.91 \pm 1.78$, and $5.44 \pm 1.90$ for infertility, emotion, menstrual problem, body weight, and body hair, respectively.

Table 4 (Part A) shows the comparison of the mean score of PCOSQ across various age groups and a high score and statistically significant differences in terms of body weight $(P<0.001)$ and infertility $(P<0.001)$ in the age group of $\leq 19$. In addition, Table 4 (Part B) presents the comparison of the mean score of the PCOS questionnaire across various BMI groups in PCOS cases. The result showed a significant difference regarding emotion $(P<0.008)$, body hair $(P<0.035)$, body weight $(P<0.001)$, and infertility $(P<0.018)$ among the groups, representing a high score in
Table 3. Mean Score of 26 Items and All Five PCOSQ Domains in the Study Population

\begin{tabular}{|c|c|}
\hline Domain & $\begin{array}{l}\text { Score } \\
\text { (Mean } \pm \text { SD) }\end{array}$ \\
\hline Emotion & $3.73 \pm 1.06$ \\
\hline Depressed as a result of having PCOS? & $4.49 \pm 1.72$ \\
\hline Easily tired? & $3.46 \pm 1.13$ \\
\hline Moody as a result of having PCOS? & $4.82 \pm 1.59$ \\
\hline Had low self-esteem a result of having PCOS? & $4.85 \pm 1.57$ \\
\hline Felt frightened of getting cancer? & $6.24 \pm 0.79$ \\
\hline Worried about having PCOS? & $4.67 \pm 1.78$ \\
\hline Self-conscious as a result of having PCOS? & $5.13 \pm 1.72$ \\
\hline Late menstrual period? & $2.45 \pm 2.11$ \\
\hline Body Hair & $5.44 \pm 1.90$ \\
\hline Growth of visible hair on the chin? & $5.31 \pm 1.95$ \\
\hline Growth of visible hair on the upper lip? & $5.36 \pm 2.07$ \\
\hline Growth of visible hair on the face? & $5.4 \pm 1.97$ \\
\hline Embarrassment about excessive body hair? & $5.58 \pm 1.92$ \\
\hline Growth of visible body hair? & $5.55 \pm 2.05$ \\
\hline Body weight & $4.91 \pm 1.78$ \\
\hline Concerned about being overweight? & $4.39 \pm 2.02$ \\
\hline Had trouble dealing with your weight? & $4.64 \pm 1.81$ \\
\hline Felt frustration in trying to lose weight? & $5.09 \pm 3.63$ \\
\hline $\begin{array}{l}\text { Feel like you are not sexy because of being } \\
\text { overweight? }\end{array}$ & $5.41 \pm 1.68$ \\
\hline Have difficulties staying at your ideal weight? & $5.03 \pm 1.88$ \\
\hline Infertility & $3.58 \pm 1.47$ \\
\hline Concerned with infertility problems? & $3.63 \pm 2.10$ \\
\hline Felt afraid of not being able to have children? & $2.73 \pm 2.08$ \\
\hline Feel a lack of control over the situation with PCOS? & $3.03 \pm 1.69$ \\
\hline Feel sad because of infertility problems? & $4.95 \pm 2.13$ \\
\hline Menstrual problem & $4.05 \pm 0.71$ \\
\hline Headaches? & $5.2 \pm 1.26$ \\
\hline Irregular menstrual periods? & $2.34 \pm 1.00$ \\
\hline Abdominal bloating? & $4.75 \pm 1.19$ \\
\hline Menstrual cramps? & $3.94 \pm 1.19$ \\
\hline
\end{tabular}

Note. PCOSQ: polycystic ovary syndrome questionnaire; SD: Standard deviation.

the group of $<18$ in comparison to the other BMI group. With respect to menstrual problems, the HRQOL score was high in the BMI $<18$ but statistically non-significant differences were observed between the groups in this regard. Table 4 (Part C) provides a comparison of the mean score of PCOSQ versus marital status in PCOS cases. Based on the results, a non-significant difference was found regarding HRQOL between married and unmarried women in terms of body hair $(P=0.513)$ and menstrual problems $(P=0.748)$. However, statistically significant differences were observed with respect to emotion ( $P=0.039)$, body weight $(P=0.002)$, and infertility $(P=0.001)$. Figure 1 displays the comparison of the mean score of PCOSQ across various educational status in PCOS cases. The result showed no statistically significant 
Table 4. Comparison of the Mean Score of PCOSQ Across Various Age Groups, BMI, and Marital Status

\begin{tabular}{|c|c|c|c|c|c|}
\hline \multicolumn{6}{|c|}{ A. Comparison of the mean score of PCOSQ across various age groups in PCOS cases } \\
\hline Domain & Age $\leq 19$ & Age $\leq \mathbf{2 0 - 3 0}$ & Age $>\mathbf{3 0}$ & \multicolumn{2}{|c|}{ Test of Significance (ANOVA) } \\
\hline Emotion & $4.0 \pm 1.15$ & $3.59 \pm 1.00$ & $3.65 \pm 01.00$ & \multicolumn{2}{|l|}{0.197} \\
\hline Body hair & $5.65 \pm 1.88$ & $5.22 \pm 01.90$ & $6.02 \pm 1.92$ & \multicolumn{2}{|l|}{0.367} \\
\hline Body weight & $5.81 \pm 1.47$ & $4.41 \pm 1.76$ & $4.66 \pm 1.80$ & \multicolumn{2}{|l|}{0.001} \\
\hline Infertility & $5.85 \pm 1.13$ & $4.35 \pm 1.62$ & $4.11 \pm 1.96$ & \multicolumn{2}{|l|}{0.001} \\
\hline Menstrual problem & $4.02 \pm 0.83$ & $4.07 \pm 0.66$ & $4.05 \pm 0.65$ & \multicolumn{2}{|l|}{0.937} \\
\hline \multicolumn{6}{|c|}{ B. Comparison of the mean score of PCOSQ across various BMIs in PCOS cases } \\
\hline Domain & $\mathrm{BMI}<18$ & BMI 18-25 & BMI >25-30 & BMI >30 & Test of Significance (ANOVA) \\
\hline Emotion & $4.18 \pm 0.66$ & $4.00 \pm 1.07$ & $3.23 \pm 0.85$ & $3.48 \pm 1.21$ & 0.008 \\
\hline Body hair & $6.02 \pm 1.43$ & $5.77 \pm 1.76$ & $4.53 \pm 2.12$ & $5.55 \pm 1.80$ & 0.035 \\
\hline Body weight & $6.70 \pm 0.35$ & $5.67 \pm 1.24$ & $3.92 \pm 1.65$ & $3.10 \pm 1.50$ & 0.001 \\
\hline Infertility & $5.72 \pm 0.96$ & $5.16 \pm 1.58$ & $4.28 \pm 1.69$ & $4.22 \pm 1.78$ & 0.018 \\
\hline Menstrual problem & $4.37 \pm 0.91$ & $4.14 \pm 0.66$ & $3.98 \pm 0.68$ & $3.73 \pm 0.72$ & 0.104 \\
\hline \multicolumn{6}{|c|}{ C. Comparison of the mean score of PCOSQ verses marital status in PCOS cases } \\
\hline Domain & Yes & No & $P$ Value & & \\
\hline Emotion & $3.50 \pm 0.92$ & $3.89 \pm 1.12$ & 0.050 & & \\
\hline Body hair & $5.59 \pm 1.77$ & $5.33 \pm 1.99$ & 0.513 & & \\
\hline Body weight & $4.25 \pm 1.63$ & $5.36 \pm 1.75$ & 0.002 & & \\
\hline Infertility & $3.41 \pm 1.47$ & $5.82 \pm 0.89$ & 0.001 & & \\
\hline Menstrual problem & $4.08 \pm 0.59$ & $4.03 \pm 0.79$ & 0.748 & & \\
\hline
\end{tabular}

Note. PCOSQ: Polycystic ovary syndrome questionnaire; BMI: Body mass index; Analysis of variance and t-test were applied for the comparison between the groups; SD: Standard deviation; Data are presented as mean \pm SD. $P<0.05$ is considered significant.

difference between all groups of the educational status of PCOS cases regarding all five domains of PCOSQ.

\section{Discussion}

This study was conducted to determine the HRQOL in PCOS women living in the north Indian population. PCOS is a major concern in young women having unique symptoms that varies greatly among the affected women as psychological stress $(9,19)$. The demographic data indicate a higher proportion of PCOS cases at young age mainly between 20 and 30 years old cases, which generates a signal of higher prevalence of PCOS cases in recent years and the effects of our changing lifestyle in disease incidence. BMI is a strong indicator of high body fatness, and in relation to PCOS, around $48 \%$ of PCOS cases have a BMI between 18 and $25(10,20)$. These data strongly support the above hypothesis indicating that lifestyle modifications not only affect PCOS cases but also new PCOS cases are on a rise (20-22). Thus, obesity is also a major concern affecting HRQOL in PCOS women. Based on our data, a higher percentage of PCOS belongs to urban areas. This strongly indicates that a sedentary lifestyle has a great impact on the development of PCOS that may be due to endocrine alterations (23). Earlier data suggested that illiteracy mainly in rural Indian populations is worse compared to the urban population (24), which is in line with the findings of our study, representing a higher literacy rate in the urban population in comparison to those in rural areas. However, it contradicts the findings of Golboni et al in terms of educational status and its relation to awareness about the disease (25). The data suggest and support previous discussions, demonstrating that even after higher education in the urban population, women were not aware of the detrimental effects of a sedentary lifestyle on health status and needed a structured awareness program for PCOS. The obtained data also indicated that some women with PCOS were from the professional background while most of them were either students or house makers (26) As previously reported, the highest population of north India belonged to the middle class in terms of income. A higher percentage (41\%) of PCOS cases were married, and thus delayed and irregular menstrual cycle, as well as willingness to conceive a child were the major reasons for treatment. As mentioned earlier, almost $99 \%$ of PCOS cases were suffering either from the delayed or irregular menstrual cycle and thus seeking treatment due to fear of infertility (27). This is well-evident that motherhood plays a very important role in women's identity and social acceptability after marriage. Therefore, infertility has always been considered as the major risk of psychological distress (Infertility stress). Thus, data demonstrated that most PCOS cases had a higher priority for pregnancy and 


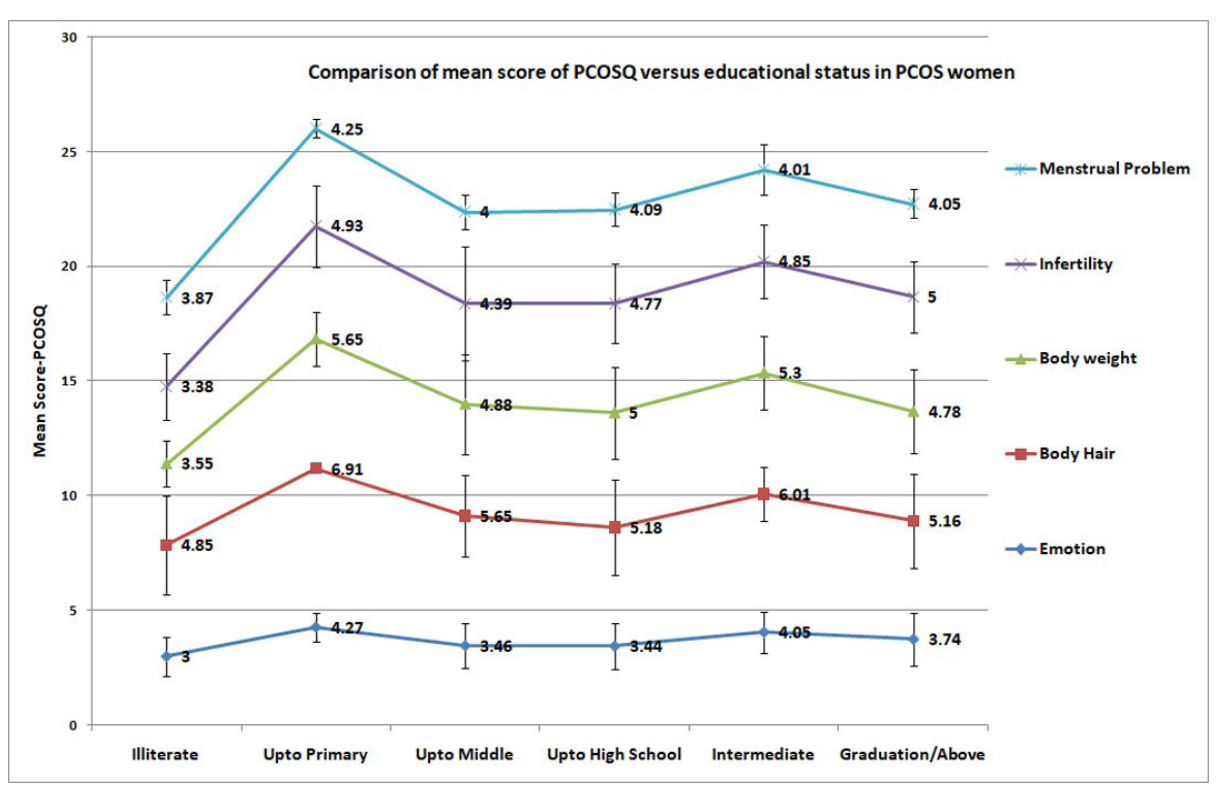

Figure 1. Comparison of the Mean Square of PCOSQ Versus Educational Status in PCOS Women

thus higher numbers of PCOS cases were taking treatment within one year. The extent of the HRQOL of PCOS cases affected due to infertility probably depends on cultural, ethnic, and social facts at certain extinct $(14,28)$. As discussed earlier, more PCOS cases were well-educated and belonged to urban or suburban areas. Moreover, these women did not rely only on vegetables and they had mixed types of eating habits and were taking a rich diet (29). The average percentage (32\%) of PCOS cases was also taking junk foods weekly once or twice. Consistent with this report, our data also reflects a good correlation between the prevalence of PCOS, eating habits, and urbanisation. In a very good agreement, BMI, sedentary lifestyle, and mixed eating habits altogether may be the reason for PCOS development and compromised HRQOL in PCOS cases. Furthermore, infertility and emotional stress obtained very low scores in comparison to a menstrual problem, body weight, and body hair in the entire five domains of PCOSQ. This strongly supports the previously discussed reason for infertility and its related stress for seeking PCOS treatment (27). The findings of the present study indicated that body hair, body weight, and an irregular menstrual cycle had lower effects on HRQOL in PCOS cases and thus created less psychological stress in comparison to infertility and emotions. Moreover, marital status greatly affected the HRQOL in terms of infertility, emotions, and body weight rather than body hair and menstrual problem (30). Consistent to the previous report, it was observed that educational status does not affect any domain of HRQOL in PCOS cases (10). In other words, the quality of life of those PCOS cases having even higher education and illiterate or less educated PCOS cases represented similar detrimental effects in the present study. In addition, body weight and infertility were greatly affected in the age group of $\leq 20$ -
30 and $>30$ compared to other domains of the HRQOL questionnaire $(6,10,31)$. As previously discussed, BMI is not only an indicator of fatness but also indirectly signifies the altered metabolism that may cause various metabolic disorders and hormonal imbalances $(32,33)$. Based on the findings of the present study, BMI greatly affected all HRQOL domains but had lower effects on the menstrual problem, which is probably because the menstrual problem is not visually or physically evidenced in society leading to the least responsibility for the development of psychological stress. Overall, social, cultural, and ethnic differences remarkably influence different domains of HRQOL independently $(14,28)$. In developed countries, obesity has a greater influence on HRQOL in comparison to developing countries $(23,34,35)$. However, menstrual irregularities greatly affect the QOL in PCOS cases based on some reports $(31,36)$.

\section{Conclusions}

Our study included PCOS cases from different socioeconomic status and urban and suburban areas. In general, our findings indicated that infertility, emotions, and body weight had a great impact on the HRQOL of women suffering from PCOS. Accordingly, we recommended both therapeutic as well as counselling strategies for patients in order to improve the QOL in PCOS cases. It should be noted that this study did not investigate any biochemical correlation related to PCOS cases and their HRQOL. Thus, it is suggested that future studies explore further correlations between HRQOL and PCOS cases.

\section{Authors' Contribution}

All the authors substantially contributed to the research and writing the manuscript. 


\section{Conflict of Interests}

Authors declare that they have no conflict of interests.

\section{Financial Support}

This study was self-funded by the first author.

\section{Acknowledgments}

The authors are thankful to the Department of Biostatistics, All India Institute of Medical Sciences, New Delhi for providing support in data analysis of this study.

\section{References}

1. World Health Organization (WHO). The Global Burden of Disease. WHO; 2004. https://www.who.int/healthinfo/ global_burden_disease/GBD_report_2004update_full.pdf. Accessed August 25, 2019.

2. Centers for Disease Control and Prevention (CDC). PCOS (Polycystic Ovary Syndrome) and Diabetes. CDC; 2019. https://www.cdc.gov/diabetes/library/spotlights/PCOS. html. Accessed August 25, 2019.

3. Sirmans SM, Pate KA. Epidemiology, diagnosis, and management of polycystic ovary syndrome. Clin Epidemiol. 2013;6:1-13. doi:10.2147/clep.s37559

4. Kalra P, Bansal B, Nag P, et al. Abdominal fat distribution and insulin resistance in Indian women with polycystic ovarian syndrome. Fertil Steril. 2009;91(4 Suppl):1437-1440. doi:10.1016/j.fertnstert.2008.06.037

5. Hacker NF. Hacker \& Moore's Essentials of Obstetrics and Gynecology. 5th ed. China: Elsevier; 2012.

6. Elsenbruch S, Hahn S, Kowalsky D, et al. Quality of life, psychosocial well-being, and sexual satisfaction in women with polycystic ovary syndrome. J Clin Endocrinol Metab. 2003;88(12):5801-5807. doi:10.1210/jc.2003-030562

7. Barry JA, Azizia MM, Hardiman PJ. Risk of endometrial, ovarian and breast cancer in women with polycystic ovary syndrome: a systematic review and meta-analysis. Hum Reprod Update. 2014;20(5):748-758. doi:10.1093/humupd/ $\mathrm{dmu} 012$

8. Revised 2003 consensus on diagnostic criteria and long-term health risks related to polycystic ovary syndrome. Fertil Steril. 2004;81(1):19-25. doi:10.1016/j. fertnstert.2003.10.004

9. Ando' A, D'Alessandro AM. Psychological implications of PCOS. In: Metabolic Aspects of PCOS. Cham: Springer; 2015:63-69. doi:10.1007/978-3-319-16760-2_4

10. Shishehgar F, Ramezani Tehrani F, Mirmiran P, Hajian S, Baghestani AR. Comparison of the association of excess weight on health related quality of life of women with polycystic ovary syndrome: an age- and BMI-matched case control study. PLoS One. 2016;11(10):e0162911. doi:10.1371/journal.pone.0162911

11. Jones GL, Hall JM, Balen AH, Ledger WL. Health-related quality of life measurement in women with polycystic ovary syndrome: a systematic review. Hum Reprod Update. 2008;14(1):15-25. doi:10.1093/humupd/dmm030

12. Costello MF, Misso ML, Balen A, et al. Evidence summaries and recommendations from the international evidencebased guideline for the assessment and management of polycystic ovary syndrome: assessment and treatment of infertility. Hum Reprod Open. 2019;2019(1):hoy021. doi:10.1093/hropen/hoy021

13. Balen AH. Polycystic ovary syndrome (PCOS). Obstet Gynaecol. 2017;19(2):119-129. doi:10.1111/tog.12345

14. Schmid J, Kirchengast S, Vytiska-Binstorfer E, Huber J. Infertility caused by PCOS--health-related quality of life among Austrian and Moslem immigrant women in Austria. Hum Reprod. 2004;19(10):2251-2257. doi:10.1093/ humrep/deh432

15. 15. National Institute for Health and Care Excellence (NICE). Fertility Problems: Assessment and Treatment. NICE; 2013. Updated Sept 2017. https://www.nice.org.uk/ guidance/cg156. Accessed September 7, 2019.

16. Jones GL, Benes K, Clark TL, et al. The polycystic ovary syndrome health-related quality of life questionnaire (PCOSQ): a validation. Hum Reprod. 2004;19(2):371-377. doi:10.1093/humrep/deh048

17. Guyatt G, Weaver B, Cronin L, Dooley JA, Azziz R. Healthrelated quality of life in women with polycystic ovary syndrome, a self-administered questionnaire, was validated. J Clin Epidemiol. 2004;57(12):1279-1287. doi:10.1016/j. jclinepi.2003.10.018

18. Cronin L, Guyatt G, Griffith L, et al. Development of a health-related quality-of-life questionnaire (PCOSQ) for women with polycystic ovary syndrome (PCOS). J Clin Endocrinol Metab. 1998;83(6):1976-1987. doi:10.1210/ jcem.83.6.4990

19. McCook JG, Reame NE, Thatcher SS. Health-related quality of life issues in women with polycystic ovary syndrome. J Obstet Gynecol Neonatal Nurs. 2005;34(1):1220. doi:10.1177/0884217504272945

20. Rich-Edwards JW, Spiegelman D, Garland M, et al. Physical activity, body mass index, and ovulatory disorder infertility. Epidemiology. 2002;13(2):184-190. doi:10.1097/00001648200203000-00013

21. Foucaut AM, Faure C, Julia C, Czernichow S, Levy R, Dupont C. Sedentary behavior, physical inactivity and body composition in relation to idiopathic infertility among men and women. PLoS One. 2019;14(4):e0210770. doi:10.1371/ journal.pone.0210770

22. Esmaeilzadeh S, Agajani Delavar M, Basirat Z, Shafi H. Physical activity and body mass index among women who have experienced infertility. Arch Med Sci. 2013;9(3):499505. doi:10.5114/aoms.2013.35342

23. Balaji S, Amadi C, Prasad S, et al. Urban rural comparisons of polycystic ovary syndrome burden among adolescent girls in a hospital setting in India. Biomed Res Int. 2015;2015:158951. doi:10.1155/2015/158951

24. Ministry of Statistics and Programme Implementation, Government of India. Literacy and Education. (Chapter 3). http://www.mospi.gov.in/sites/default/files/reports_ and_publication/statistical_publication/social_statistics/ Chapter_3.pdf.

25. Golboni F, Nadrian H, Najafi S, Shirzadi S, Mahmoodi H. Urban-rural differences in health literacy and its determinants in Iran: a community-based study. Aust J Rural Health. 2018;26(2):98-105. doi:10.1111/ajr.12378

26. Chatterjee E, Desai S, Vanneman R. Indian paradox: rising education, declining womens' employment. Demogr Res. 2018;38:855-878. doi:10.4054/DemRes.2018.38.31

27. Trent ME, Rich M, Austin SB, Gordon CM. Fertility concerns and sexual behavior in adolescent girls with 
polycystic ovary syndrome: implications for quality of life. J Pediatr Adolesc Gynecol. 2003;16(1):33-37. doi:10.1016/ s1083-3188(02)00205-x

28. Wijeyaratne CN, Dilini Udayangani SA, Balen AH. Ethnic-specific polycystic ovary syndrome: epidemiology, significance and implications. Expert Rev Endocrinol Metab. 2013;8(1):71-79. doi:10.1586/eem.12.73

29. Kulkarni SD, Patil AN, Gudi A, Homburg R, Conway GS. Changes in diet composition with urbanization and its effect on the polycystic ovarian syndrome phenotype in a Western Indian population. Fertil Steril. 2019;112(4):758763. doi:10.1016/j.fertnstert.2019.05.021

30. Ferreira M, Antunes L, Duarte J, Chaves C. Influence of infertility and fertility adjustment on marital satisfaction. Procedia Soc Behav Sci. 2015;171:96-103. doi:10.1016/j. sbspro.2015.01.094

31. Kaczmarek C, Haller DM, Yaron M. Health-related quality of life in adolescents and young adults with polycystic ovary syndrome: a systematic review. J Pediatr Adolesc Gynecol. 2016;29(6):551-557. doi:10.1016/j.jpag.2016.05.006

32. Garrow JS, Webster J. Quetelet's index (W/H2) as a measure of fatness. Int J Obes. 1985;9(2):147-153.

33. Lim SS, Kakoly NS, Tan JWJ, et al. Metabolic syndrome in polycystic ovary syndrome: a systematic review, metaanalysis and meta-regression. Obes Rev. 2019;20(2):339352. doi:10.1111/obr.12762

34. Benetti-Pinto CL, Ferreira SR, Antunes A Jr, Yela DA. The influence of body weight on sexual function and quality of life in women with polycystic ovary syndrome. Arch Gynecol Obstet. 2015;291(2):451-455. doi:10.1007/s00404014-3423-1

35. Hashimoto DM, Schmid J, Martins FM, et al. The impact of the weight status on subjective symptomatology of the Polycystic Ovary Syndrome: a cross-cultural comparison between Brazilian and Austrian women. Anthropol Anz. 2003;61(3):297-310.

36. Borghi L, Leone D, Vegni E, et al. Psychological distress, anger and quality of life in polycystic ovary syndrome: associations with biochemical, phenotypical andsociodemographic factors. J Psychosom Obstet Gynaecol. 2018;39(2):128-137. doi:10.1080/0167482x.2017.1311319

(c) 2020 The Author(s); This is an open-access article distributed under the terms of the Creative Commons Attribution License (http:// creativecommons.org/licenses/by/4.0), which permits unrestricted use, distribution, and reproduction in any medium, provided the original work is properly cited. 